\title{
ENTRE A EDUCAÇÃO E A POLÍTICA: A COLONIALIDADE
}

\author{
wanderson flor do nascimento ${ }^{1}$
}

\begin{abstract}
"Os filósofos nos legaram uma verdade análoga à dos poetas", nos disse José Carlos Mariátegui. Rilke sugeriu,

com efeito, que as pessoas vivem e se olham viver ao

mesmo tempo. Viver e olhar-se viver não são, por consequência, sucessivos. Estão cada um no outro, todo o tempo. Olhar-se viver (o conhecimento) é parte do ato de

viver e vice-versa. A realidade nos é dada a conhecer porque somos parte dela. Quanto mais profunda e totalmente buscamos conhecê-la, tanto mais total e profundamente estamos implicados nela. Segundo esta perspectiva, o conhecimento não é só, e talvez nem tanto, uma questão epistemológica. É igualmente uma questão ética [e política]. (QUIJANO, 1994, p. XV)
\end{abstract}

Nosso tempo, a Modernidade, tem uma história nebulosa, que muitas vezes nos é contada apenas como a história das Luzes, da emancipação, das liberdades, da igualdade, da saída dos indivíduos de sua minoridade auto-culpada. Entretanto, esta maneira de contar a história silenciou e ocultou uma série de gestos violentos, obscuros, nefastos que são tão componentes desse trajeto histórico como esses valores que nos foram ressaltados. Será possivel contar esta história de outra maneira? Será possível resgatar um espaço para outras vozes, as silenciadas, no contexto de nosso tempo?

A educação que experimentamos hoje é uma educação moderna ou que aspira modernizar-se. Mas em que medida essa modernização da educação não nos colocaria diante deste silenciamento e destes gestos violentos que a história da modernidade ocultou? Será que o oculto deixa de agir por não ser aparente?

Quando pensamos em uma poética da/na educação $e$ estamos diante deste mundo moderno que, bipartido, separa a linguagem poética da linguagem

\footnotetext{
${ }^{1}$ Professor do Departamento de Filosofia e do Programa de Pós-Graduação em Bioética da Universidade de Brasília. E-mail: wandersonn@gmail.com.
}

FLOR DO NASCIMENTO, wanderson. Entre a educação e a política: a colonialidade. Revista Sul-Americana de Filosofia e Educação. Número 23: nov/2014-abr/2015, p. 444458. 
denotativa, esta última que comunica o mundo de modo funcional-veritativo. Mas, neste cenário no qual as práticas educativas se configuram neste espaço que oculta a violência dos gestos que constituíram a modernidade, como evitar que a própria poética seja entendida como uma estetização dessa violência que perpassa a prática educacional?

Talvez uma maneira de buscar ouvir essas outras vozes - e, também, abrir espaço para uma poética que não se afirme de modo moderno, neste cenário já binarizado, que parece apenas estetizar o já dado, transformando apenas sua superfície - seja entender o movimento que fez da modernidade e das práticas e sentidos educacionais modernos, um movimento que nasce binarizado $e$ binarizante, mostrando o que lhe convém (sua face luminosa) e ocultando seu lado sombrio e violento. Nessa tarefa, compreender o que algumas vozes insurgentes têm dito sobre a história da modernidade, desde a perspectiva da América Latina, pode ser interessante e potencializador.

\section{Contando de outro modo a história da modernidade: a colonialidade}

Era uma vez... Esta maneira de iniciar muitas das narrativas nos remete a um olhar sobre o tempo. Esta "vez", à qual se refere a expressão, nos aponta para uma perspectiva de algo que se deu a bastante tempo, sobre o qual temos apenas uma remota, mas vívida lembrança que vale a pena ser recontada. Mas também se refere a uma alternativa, a um certo modo de contar esta narrativa que substitui os três pontos...

Como toda narrativa, a história também tem muitos modos de ser contada. Nunca é apenas um fato que está pronto, lá atrás, que será apenas rememorado e meramente comunicado pela narração. Walter Benjamin nos lembra que no gesto de contar a história está sempre um interesse, um jogo de forças que se mostra como um "salto do tigre para o passado" (BENJAMIN, 2012, p. 18). Deste modo, embora seja precipitado dizer que a história é meramente contada pelos vencedores, podemos dizer que, na narrativa histórica, os olhares se 
posicionam de modos distintos nas narrativas que se hegemonizam e nas que seguem silenciadas.

Nas narrativas sobre modernidade, o "Era uma vez...", normalmente reproduzido, pensa as maneiras de ver europeias como privilegiadas no horizonte dos processos civilizatórios. A chegada de espanhóis e portugueses ao nosso continente é, muitas vezes, interpretado como um fenômeno que desenvolveu o nosso mundo. A "descoberta" fez bem não apenas para a futura Europa, como também fez bem para o "novo mundo descoberto", que era marcado pela barbárie, pelo atraso e pelo primitivismo.

Uma série de novos narradores buscam contar essa história de outro modo. Pensadoras e pensadores da América Latina, desde a década de 90 do século passado partem da percepção que se olharmos a história, tal como ela pode ser contada a partir de nosso continente, veremos a Modernidade de uma maneira radicalmente diferente. Este grupo de pesquisadoras e pesquisadores veem na chegada dos europeus a nossas terras como o fato que inaugura a Modernidade: em um primeiro nível, histórico e, em outro, filosófico (QUIJANO, 2000; GROSFOGUEL, 2012).

É com a conquista da América que o mundo modifica as diversas experiências com a própria mundanidade, com as pessoas entre si e com as outras, com o conhecimento, com o trabalho, com o corpo e com a linguagem. Dussel (1993) nos diz que a modernidade é um fato europeu, que finda por se mundializar através da colonização. Com a Modernidade, um novo padrão de poder passa a funcionar: a colonialidade, que nasce localmente, na relação entre Europa e América Latina, mas que se globaliza, funcionando após algum tempo em todo o planeta, embora com algumas fissuras e pequenas crises (MIGNOLO, 2003).

Este padrão de poder tem como características pensar a classificação das populações em termos raciais, estabelecer o modo de produção de conhecimento da Europa como o válido e legítimo, direcionar o sentido do trabalho para a 
produção e reprodução do capital e legitimar a autoridade coletiva em torno da ideia de Estado-Nação (QUIJANO, 2000).

Nessa maneira de contar a história da Modernidade, tendo a colonialidade como um eixo de interpretação, ressalta-se o fato de que a raça, primeiro dos pilares da colonialidade, aparece não como uma ideia que descreve a natureza dos seres humanos, mas surge como uma maneira de naturalizar as relações de opressão que se instituem na relação entre quem coloniza e quem é colonizado. Ou seja, a raça passa a ser um signo de hierarquização, que descreverá e prescreverá as relações entre as populações em termos de uma estratificação opressiva, não denotando meramente as diferenças, mas valorando-as, em torno de assimetrias de poder (SEGATO, 2007, p. 131-150).

Os debates em torno da ideia de raça, tanto os que se instalaram no início da Modernidade, como o Controvérsia de Valladolid, quanto as mais tardias, como a instituição da ideia biológica de raça, no século XIX, são marcas de uma articulação de poder nas instâncias sociais que têm como objetivo justificar $e$ articular posições de dominação nos contextos coloniais. Com as críticas recentes à ideia de raça e sua superação pela própria biologia, ela se explicita no que sempre foi: um construto político. E, ainda hoje, funciona como um marcador de populações que orienta, inclusive, as políticas.

"Raça", hoje, funciona como um marcador de hierarquia em contextos virtual ou efetivamente concretos. A ideia de raça, ao perder sua caracterização biológica, persiste como uma marca que define lugares políticos com uma diferença de força ou um signo da hierarquização violenta, da constituição inferiorizada da alteridade, que varia em contextos distintos, mas que marca sempre os lugares de privilégios e nas relações assimétricas, imprimindo nos corpos as marcas de uma história e não identificando algo já pré-existente (condições biológicas). De modo que podemos hoje encontrar o uso da ideia de raça servindo para classificar as populações para além de sua cor, origem, pertença cultural, religiosa ou qualquer outro caractere agrupador, mas para classificar qualquer instância historicamente construída da desigualdade. 
Essas relações assimétricas também se aplicam aos modos de produzir conhecimento. Walter Mignolo (2003) nos conta que os primeiros contatos epistêmicos que ocorreram entre os espanhóis e as populações originárias de nosso continente, se deram pela identificação de que estes não tinham uma escrita alfabética, ou seja, definiram os indígenas em função de uma falta, daquilo que a Europa tinha e aqueles povos não. E essa falta foi constituída de modo que a relação, através da linguagem, se desse também de modo assimetricamente hierarquizado: quem tem essa escrita - os europeus - produz conhecimento verdadeiro e quem não tem - os "outros" - produz apenas cultura e, ainda assim, uma cultura atrasada, primitiva.

De alguma maneira, esta cisão do conhecimento em torno da escrita finda, também, por contribuir para a criação essa dicotomia sobre a qual nos referimos entre a linguagem poética e a linguagem denotativa, sendo esta última, verdadeiramente adequada à ciência. Este binarismo em torno da razão e do sensível que se instala na percepção moderna sobre a linguagem também se deu em torno de hierarquizações, na qual para o que importa, o que é sério, usa-se a linguagem não poética, impessoal, neutra, universal, racional.

Este registro colonial, que nasce no início dos processos de conquista de nosso continente persiste ainda hoje, estruturando relações, identidades, modos de percepções da realidade, das pessoas, dos valores e dos conhecimentos, hierarquizando poderes, saberes, linguagens, experiências e vidas. Este mesmo registro fez com que apenas parte da história de nossa Modernidade nos fosse contada, mudando ou ocultando lugares e a importância histórica de quem participou - ou sofreu - os gestos que fundaram este nosso período moderno, que ora desejamos, ora festejamos...

\section{A educação em meandros coloniais}

Uma das vozes, ou instrumentos, que contam essa história da Modernidade é a educação, que não é um instrumento qualquer, é um dessas ferramentas que são construídas pelo próprio objeto sobre o qual opera. Deste 
modo, a própria educação, ao nos contar uma história da Modernidade, acaba por fazer-se neste contar, neste narrar, desde uma perspectiva que silencia ao fazer apenas algumas vozes falarem, ao contar apenas parte do que se sabe. Esta narrativa faz aparecer apenas o aspecto glorioso da história da Modernidade, o que venceu, sem mostrar que no gesto de vencer, não apenas constituíram-se perdedores, mas estraçalhou-se a experiência de vários povos, várias_vozes subsomem-se. E, nesse cenário, a educação, ela mesma, acaba por assumir um desses sentidos da Modernidade: seu caráter libertador ou emancipador e ocultar seu traço violento.

Um dos capítulos iniciais da história que nos é contada sobre a Modernidade e seus gestos violentos, em voz baixa, num sussurro que busca esconder coisas importantes, é o episódio da chamada controvérsia de Valladolid ocorrida na Espanha em 1550. Ali, está em jogo a discussão sobre as relações que as missões coloniais poderiam estabelecer com as populações originárias desse lugar que hoje chamamos de continente americano. A pergunta chave era: A coroa espanhola pode guerrear contra os indígenas para evangelizá-los? Nesse embate, se enfrentam Ginés de Sepúlveda e Bartolomé de Las Casas; o primeiro defendendo que a coroa tinha não apenas o direito, mas o dever de estabelecer a guerra como um meio para o fim da evangelização, e o segundo condenando a possibilidade de que a guerra seja um meio legítimo para a empreitada evangelizadora_(LAS CASAS, 2010, p. 119-213).

Na trama dessa parte da história da Modernidade, a educação aparece como um horizonte fundamental. A guerra seria justa para a tarefa da evangelização que se mostraria como uma educação para a salvação e para a civilidade. Evangelizar seria uma prática educativa que seria o fim perseguido pelos meios que se definissem neste debate. A vitória da posição de Las Casas não implicou, obviamente, em um processo que protegesse os indígenas das violências coloniais. Mas findou por naturalizar e fazer vencer um conjunto de imagens que perdurariam nos outros capítulos da história da Modernidade. 
Maximiliano López (2008) nos lembra que a infância era uma metáfora normalmente usada, tanto na posição de Sepúlveda como na de Las Casas: uma delas implicando a imaturidade e a incivilidade da infância e a outra implicando sua ingenuidade, mostrando um aspecto ambíguo das interpretações sobre a infância. E, juntamente com a ideia de que não deveríamos fazer uma guerra para evangelizar os povos indígenas, firmou-se uma imagem que subvalorizou a infância como esta experiência temporal da humanidade que precisa de tutela e para a qual a educação evangelizadora seria um esteio de salvação. Assim, forja-se uma imagem da infância, juntamente com uma imagem da própria educação.

Essa imagem educativa messiânica que surge como consequência das narrativas do início da Modernidade - e que supõe a infância como uma experiência ingênua que deve ser superada pelos processos educativos - nos lega uma infância a ser tutelada e uma educação tutelante. O gesto tutelar supõe uma hierarquização entre quem tutela e quem é tutelado, afirmando uma distância entre ambos que deve ser superada se o processo tutelar da educação/evangelização funcionar, fazendo com que os tutelados deixem de ser infantis e passando a ser outra coisa que não o que já são, aproximando-se, tanto quanto possível, da imagem de humano que quem mantém a tutela faz de si mesmo.

Civilizar seria isso: imprimir no outro a imagem que faço, como positiva, de mim mesmo, enquanto colonizador/civilizado. E, deste modo, vemos uma parte do contexto que fez com que a educação ocupasse esse espaço colonial/civilizador. Esta prática educacional é, também, subjetivadora. Não apenas ensina algo a alguém, mas ensina alguém a ser. E esse tornar-se educacional, em contextos coloniais, é sempre atravessado pelo poder hierarquizante, progressivo e ensina, também, a estabelecer relações: dos sujeitos consigo mesmos e com os outros.

Não é sem razão que os chamados "quatro pilares da educação" aprender a conhecer, aprender a fazer, aprender a viver juntos e aprender a ser(UNESCO, 1998) trazem elementos que enfatizam os dois últimos pilares, que são perpassados por elementos de poder que lidam com os modos como os sujeitos veem a si mesmos, as outras pessoas e o mundo. Ao mesmo tempo em que afirma 
aprender conhecer e fazer (que já seriam enfatizados pelas dinâmicas usuais da educação), afirma também uma instância subjetivadora e interventora nas relações entre as pessoas. Não se aprende a ser qualquer coisa e, muito menos a conviver de qualquer maneira. Há uma abertura que abriga uma suposta liberdade que deve ser direcionada para a "partilha" de um mundo melhor, articulada por uma imagem do que seria tal mundo. Esta imagem é exatamente fundada pelos conhecimentos que são instrumentalizados e gerados no contexto desta colonialModernidade. A população, vista como ocupante de uma posição infantil, em um sentido pejorativo é, assim, manipulada e governada através destes princípios educativos, destes pilares da educação, que colonizam os nossos imaginários, fazendo com que narremos sempre a mesma história, ocultando o próprio processo que gera esse apagamento de gestos que se instituem em meios de assimetria.

Por meio dos novos discursos pedagógicos, observamos que o desenvolvimento de habilidades e competências se orienta por um padrão de excelência a ser alcançado. E, efetivamente, quem atinge esses padrões ou, mais precisamente, quem mais deles se aproxima, estaria em uma posição epistêmica $e$ socialmente superior a quem não os atingem ou deles não se aproximem.

Embora os discursos sobre competências e habilidades asseverarem que a experiência da/o educanda/o é base orientadora para o processo da aprendizagem, o que elas efetivam é um espaço competitivo que hierarquiza e padroniza sujeitos. Os saberes locais são normalmente encarados como supersticiosos. Nesse contexto, a superstição não é dispensável, mas é necessário que, na busca do avanço de nosso processo de desenvolvimento, nos aproximemos de um saber cada vez mais verdadeiro e autêntico, que nos insira na globalidade do mundo, ou seja, em sua totalidade, para sobrepor-se, então, a esses saberes supersticiosos. Se estes saberes, os mais autênticos que supersticiosos, não forem "verdadeiros", eles seriam, ao menos, mais eficazes para resolvermos os problemas modernos de nossa da vida.

Como a vida moderna é atravessada por valores hierarquizantes, nos preparamos, por meio do desenvolvimento das citadas competências (também estruturadoras de hierarquias) para uma vida marcada por esse espaço de exclusão 
de "outras vozes", que é típico da Modernidade, muito embora esta característica seja vista apenas nas sombras da narrativa da história de nosso devir moderno.

E este não é um apresto para que aprendamos a ouvir essas vozes outras, mas uma preparação para tolerá-las e superá-las na medida em que nos esforcemos por modernizá-las, introduzindo-as em outros registros de linguagens $e$ saberes. E assim, escolarmente, modernizamos a experiência da infância, da indigenitude, da negritude, das culturas não modernas.

Lidamos com todas essas experiências na tentativa de gerar uma articulação moderna, que a tudo respeita, mas também a tudo assimila, se esforçando por modernizar tudo com o que entra em relação. E, assim, essa receptividade da diferença aparece como uma tentativa de superá-la, de conciliá-la com o ideal moderno, de assemelhá-la com o que parecer mais adequado aos processos progressivos modernos.

Tomamos a voz da/o estudante, da criança como aquela voz que ainda tem muito o que aprender para se tornar o que deve ser: um ser humano pleno, desenvolvido. A captura da experiência, fazendo-a aparecer como algo a ser entendido e desenvolvido faz da rica experiência o pobre espaço do que pode ser levado em consideração apenas na medida em que se adéqua ao modelo desenvolvimentista.

A hierarquização entre os saberes formais e informais, globais e locais, entre a linguagem denotativa e poética, baseada em um ideal progressivo de desenvolvimento supõe que todas as experiências sejam válidas, mas umas são mais importantes que as outras. A experiência canonizada pela cultura moderna deve ser a baliza e o critério de avaliação das outras. Os saberes subalternizados são, desta maneira, silenciados, na medida em que só são escutados através do filtro colonial de entendimento e avaliação do que seja um saber ou uma experiência autenticamente importante. E esse silenciamento se dá também no estabelecimento do modo correto de lidar com os saberes e as experiências. O modo hierarquizante de lidar com os saberes determina também um certo tipo de epistemologia da construção correta dos saberes que secundariza um modo não 
hegemônico de produção de pensamento, experiência, conhecimentos, linguagens, subjetividades.

E a universidade e a escola aparecem, neste contexto, como duas das principais instituições onde esse processo se exerce, se reforça, se legitima, se reproduz. A suposta acolhida à experiência da/o educanda/o por parte dos processos pedagógicos modernos esconde a perigosa armadilha de acolhê-los apenas na medida em que, com essas experiências, quer-se fazer uma nova elaboração: mais desenvolvida, mais progredida, mais moderna.

As práticas educativas escolares, findaram por aparecer, nesse contexto, como um potente mecanismo de reprodução dos enredos coloniais subalternizando experiências, colonizando histórias, incitando gestos violentos que se ocultam nas boas intenções modernizadoras.

\section{Por um esboço de descolonização escolar ou educativa}

Se pudermos considerar com relevante essa outra maneira de contar a nossa história moderna, atravessada e constituída pela colonialidade, no que diz respeito à configuração de um regime de poder que coloniza, que só existe na medida em que institui um modo de saber (e de construção ou aquisição dos saberes) e também a ideia de que as instituições modernas, entre elas a escola - $e$ também a infância, entendida, como nos lembra Ariès (1986, p. 177), como uma experiência de um sentimento que surge na Modernidade - legitimam e fazem funcionar esse esquema de colonialidade, nos colocaremos a tarefa, na medida em que quisermos liberar o mundo moderno e suas instituições dos grilhões coloniais, de promover uma transformação dos modos através dos quais lidamos com as experiências, os saberes, as práticas, as instituições, com a escola, com a educação.

As tentativas de descolonização nos colocam desafios que são muitos $e$ complexos. E, talvez, a primeira tarefa seja a de conseguir estabelecer uma crítica da modernidade entendida como atravessada e constituída pela colonialidade. $\mathrm{E}$ uma crítica da escola moderna passa também por esse processo. 
Um dos movimentos mais importantes dessa crítica é a problematização da hierarquia naturalizada de elementos da escola, que supõe um sentido progressivo das práticas pedagógicas e dos currículos. A ideia de que exista um percurso ascendente na trajetória escolar, que haja uma hierarquia "natural" entre docentes e estudantes precisam estar sob suspeita. Estas imagens são também responsáveis por manter o modelo colonial de poderes e saberes na escola, contribuindo para a formação de uma subjetividade colonizada, que precisa ser criticada na liberação de uma criação interexperiencial e intercultural no espaço escolar.

O que se propõe não é desqualificar o papel docente, mas pensá-lo de outras formas; pensar se não são possíveis outras relações entre docentes $e$ estudantes que não sejam centradas na vivência da colonialidade das relações pedagógicas. Uma escola ciente de sua formação histórica atravessada pela lógica colonial, que conjuntamente problematiza esta mesma colonialidade; Uma escola que percebe que esta hierarquia está, em grande parte, fundada em uma percepção da diferença, que a pensa em termos hierarquizados e, por isso, pode problematizar tal relação com a diferença, com a singularidade, com a diversidade de experiências, saberes e inserções culturais. Esse processo de problematização precisaria acontecer através do esforço do conjunto da comunidade escolar, que é quem tem a possibilidade, a partir de suas maneiras locais de interpretar as vivências, de criar um espaço mais propício para essa tarefa, sem um objetivo meramente salvacionista.

Um outro passo seria buscar a criação de um conjunto de condições, ainda aberto, de acolhimento dos elementos que foram colonizados sem utilizar estratégias colonizadoras. Nesta escola que se tenta descolonizar, as vozes locais são ouvidas, as experiências locais são acolhidas não na tentativa de desenvolvêlas, mas de ter este mesmo local como um dos marcos da subjetivação, sem a ideia de que o local deva necessariamente se integrar à dinâmica global. A questão aqui não é abandonar as construções globais que possam favorecer as comunidades locais, mas ter essa "integração" ou a interação com outras culturas, outras experiências (as hegemônicas), como uma possibilidade, e não como uma tarefa compulsória de quem queira se desenvolver, se modernizar. Ou seja, a necessidade 
de lidar com a experiência do local sem a finalidade de, em algum momento, a obrigação de abandoná-la em nome de uma experiência mais madura, mais racional, mais eficiente, mais desenvolvida. É uma tarefa de vivenciar a escola como um espaço dos possíveis, e não das necessidades pensadas pela marca do progresso, do desenvolvimento, da modernização, que são o plano de fundo da busca pelo "desenvolvimento" das competências e habilidades.

Este acolhimento das experiências locais deve ser sempre e, a cada vez, autocrítico. A tarefa autocrítica é fundamental para não fazermos juízos de valor, a priori, das culturas, das práticas, dos pensamentos que estão dispostas pela dinâmica da colonialidade. Isso significa pensar que não necessariamente tudo o que vem do local seja "bom" e que tudo o que está colocado pelas estratégias globais/coloniais seja "ruim". A relação com o local, assim como com o global, deve ser objeto de crítica.

E esse não é o tipo de crítica que procura desenvolver, fazer progredir o que se critica; mas o tipo de crítica que procura ver os efeitos coloniais de adoção ou abandono de uma experiência, pensamento ou prática. A crítica descolonial tem em sua base o rastreio dos ranços coloniais em nossas práticas, pensamentos, instituições. E, por isso, deve ser, o tempo inteiro, re-pensada e recolocada. A crítica descolonial é, ao mesmo tempo, uma crítica ao colonial e uma autocrítica. Não propõe um abandono das heranças europeias, mas uma relação dialógica com ela. E não devemos entender aqui o termo "dialógico", como a marca de um diálogo mediado por uma razão esclarecida - ou em busca de um esclarecimento , como o proporia Habermas, mas um diálogo que dá a conhecer e busca aproximar diversas experiências sem as hierarquizar $e$ atento ao risco da estratificação e do aprofundamento das assimetrias de poder. Nesse sentido, a crítica descolonial instaura uma proposta de lidar com as contribuições globais como uma entre outras e não como a contribuição privilegiada, por ela ter vindo de um mundo em um "estágio posterior de desenvolvimento", assim também como não se "endeusará" a experiência local como se ela não tivesse nunca a possibilidade de apresentar problemas. Todas as partes do diálogo poderão $e$ deverão ser objeto da crítica e da autocrítica. 
Arrisco aqui alguns convites iniciais a serem pensados conjuntamente por quem se interessar pelo projeto descolonização; convite este que pode ser ampliado, modificado, refeito. Este convite faz uma aposta: de que uma escola descolonial possa ser um espaço de criação e de resistência; de uma resistência criadora, de uma criação resistente. É um convite que não se torna um imperativo, como se fosse a única possibilidade de abrir um espaço escolar não colonizado, mas como uma proposta que parece coerente com as imagens críticas que nos tem apresentado os estudos sobre a colonialidade, mas que não pode supor que a única possibilidade de descolonização seja a que aparece por meio dessa afirmação do local e da recusa do global.

Por outro lado, poderíamos insistir na busca de outros espaços, para vozes outras, que foram silenciadas nessa narrativa padrão de nossa Modernidade que atravessa as escolas. Isso implicaria em ouvi-las em outras linguagens e, assim, buscarmos outros espaços para o poético na educação. Talvez seja interessante pensar a poética como resistência à colonialidade (refazer as heterarquias, recusar as hierarquias, afirmar o singular, visibilizar outros saberes, produzir outras práticas, ouvir outras vozes), estratégias possíveis através da construção de uma educação poética ou de uma poética da educação. Seria preciso criar novas visibilidades para nossas experiências e para nossas relações com o mundo.

Talvez descolonizar a educação deva implicar em inverter as evidências que se assentaram em torno dos quatro pilares da educação: desaprender a fazer o que se nos vem ensinando a fazer; desaprender a aprender o que se nos vem sendo ensinado a aprender; desaprender a viver junto nas relações competitivas nas quais somos cotidianamente ensinados a conviver; desaprender a ser o que somos. E a poética pode ser uma experiência potente nesse sentido.

A Modernidade opôs as experiências política e poética. Imaginação, intuição e criação passam a se contrapor a descrição, razão e veredicção na relação com os saberes. Recuperar uma dimensão poética de nossa relação com a linguagem, com o mundo e conosco mesmas implica em compreender a estratégia despoetizante da Modernidade. 
Aqui, essas vozes silenciadas podem ser bastante interessantes como campos de atuação descoloniais e abertos a uma crítica à despoetização da educação moderna. Um exemplo disto, entre tantos outros, poderia ser visto entre as vozes silenciadas africanas tradicionais, para as quais todo o modo de falar seria em alguma dimensão, poético, não havendo uma 'exterioridade' ao modo poético de expressão, não havendo, portanto uma distinção entre uma linguagem denotativa e poética, não sendo, portanto, significativo em falar em poética, em um sentido moderno. Este poderia ser um ponto interessante para um diálogo com as tradições ancestrais do próprio ocidente, para as quais também não havia uma ruptura entre o poético e o restante da experiência vivida e expressa. Essas perspectivas não binárias da linguagem, fazem também com que a educação não seja vista de modo opositor entre um saber e um não saber expressar a linguagem adequada à construção e à circulação de saberes.

Essa é apenas uma das possibilidades que se abrem em uma percepção descolonizada dos processos educacionais. Uma das maneiras de poder resgatar os diversos modos de contar as nossas histórias e, assim, de nos contarmos. Quem sabe esta reflexão, que se mostra como um convite, seja uma letra nessa proposta de repensar as nossas narrativas sobre nosso tempo e sobre nós. Quem sabe possamos, por caminhos diversos, abrir espaços para uma educação que nos ensine a nos narrarmos de maneiras outras, libertadoras, plurais.

\section{Referências}

ARIÈS, Phillippe. História social da criança e da família. Rio de Janeiro: Guanabara, 1986.

BENJAMIN, Walter. O anjo da história. Organização e tradução de João Barreto. Belo Horizonte: Autêntica, 2012.

DUSSEL, Enrique. 1492: O encobrimento do outro. A origem do Mito da Modernidade. Petrópolis: Vozes, 1993.

GROSFOGUEL, Ramón. Para descolonizar os estudos de economia política e os estudos pós-coloniais: transmodernidade, pensamento de fronteira e colonialidade global. In: SANTOS; Boaventura de Sousa; MENESES, Maria Paula (orgs.). Epistemologias do Sul. São Paulo: Cortez, p. 455-491, 2010. 
LAS CASAS, Bartolomé de. Liberdade e justiça para os povos da América. São Paulo: Paulus, 2010.

LÓPEZ, Maximiliano Valerio. Infancia y Colonialismo. Cuestiones de Filosofía, n. 10, 2008, p. 49-57.

MIGNOLO, Walter. Historias locales - diseños globales: colonialidad, conocimientos subalternos y pensamiento fronterizo. Madrid: Akal, 2003.

QUIJANO, Aníbal. El Sueño Dogmático. In: DÍAZ, Oswaldo Fernández. Mariátegui o la Experiencia del Otro. Lima: Amauta, p. XI- XV, 1994.

QUIJANO, Aníbal. Colonialidad del poder y clasificación social. Journal of WorldSystems Research. Santa Cruz/California, VI, 2, summer/fall, p. 342-386, 2000.

SEGATO, Rita. La Nación y sus Otros: Raza, etnicidad y diversidad religiosa en tiempos de Políticas de la Identidad. Buenos Aires: Prometeo, 2007.

UNESCO. Educação: Um tesouro a descobrir. Brasília/São Paulo: Unesco/Cortez, 1998. 